Original Research Paper

\title{
Impact of Vitamin B17 Against Growth of Colitis Bearing Mice Induced Variations in Colon Structure, AFP, CEA and PCNA Immunoreactivity
}

\author{
${ }^{1}$ Gihan Hosny Abd Elsamie, ${ }^{1}$ Sabah Gaber El-Banna, *22 Ehab Tousson, \\ ${ }^{3}$ Shatha Ghazi Felemban and ${ }^{1}$ Mohanad Salam Hussein \\ ${ }^{1}$ Department of Environmental Studies, Institute of Graduate Studies and Research, Alexandria University, Egypt \\ ${ }^{2}$ Department of Zoology, Faculty of Science, Tanta University, Egypt \\ ${ }^{3}$ Medical Laboratory Science, Fakeeh College for Medical Science, Jeddah 21461, Saudi Arabia
}

\author{
Article history \\ Received: 10-05-2021 \\ Revised: $13-07-0-2021$ \\ Accepted: 20-07-2021 \\ Corresponding Author: \\ Ehab Tousson \\ Department of Zoology, Faculty \\ of Science, Tanta University, \\ Egypt \\ Email: toussonehab@yahoo.com \\ ehabtousson@science.tanta.edu.eg
}

\begin{abstract}
Colitis alludes to inflammation of the internal coating of the colon that accompanied clinically through abdominal pains, diarrhea, weight loss, nausea. Current study aimed to study the impact of vitamin B17 against growth of colitis bearing mice induced variations in colon structure, AFP, CEA and PCNA immune reactivity. Forty female Swiss albino mice separated into 4 groups (Control, vitamin B17, colitis and post treated colitis with vitamin B17 groups). Our results revealed significant increase in serum AFP, CEA, colon injury and PCNA expressions. In contrast; post treated colitis with vitamin B17 improved the colon functions and structure, inhibit the proliferations, AFP and CEA. If established in human beings, these outcomes could recommend that; vitamin B17 can be utilized as an adjuvant treatment with chemotherapy drugs.
\end{abstract}

Keywords: Colitis, Vitamin B17, Mice, Tumor Markers, PCNA Expressions

\section{Introduction}

The colon is a significant piece of the gastrointestinal lot. Its capacities incorporate re-take-up of liquids and electrolytes just as capacity and end of rest results of food. Colitis suggests the irritation in the inward covering of the colon (Ali et al., 2018). There are different purposes behind colitis including defilement brought about by an infection or a parasite, Crohn illness, absence of blood stream and radiation colitis and injuries (Ohlsson, 2015; Saad et al., 2019). Colitis influences the distal piece of the colon and makes non-transmural irritation, huge rot and ulceration in the layers of mucosa and submucosa (Randhawa et al., 2014). These sicknesses are characterized clinically through provocative confusion in gastrointestinal lot went with looseness of the bowels, torments in midsection, weight decrease, nausea and obsessive changes like a deficiency of mucosal dysfunctions, aggravation and cell invasion (Cengiz et al., 2017). Acceptance of colitis may be because of the openness to various incendiary specialists and because of creation of free extremists (Hanauer, 2006; Saad et al., 2019). Furthermore, free extremists lessen cell reinforcement specialists and along these lines increment the seriousness of the illness (Radko and Cybulski, 2007).
So far there are three distinguished models used to initiate test colitis in rodents and mice (Antoniou et al., 2016). These models incorporate dextran sulfate sodium, oxalone and acidic corrosive (Tahan et al., 2011; Ali et al., 2018). The utilization of correlative and elective medication has consistently expanded over the previous many years (Salama et al., 2014; Tousson et al., 2018; Abd Eldaim et al., 2019a). In these examinations, a few phytochemicals were exhibited to be protected and conceivably valuable remedially (Abd Eldaim et al., 2019b; Tousson et al., 2019; Altwaijry et al., 2020, 2021). Phytochemicals are normal composites that have exercises against oxidation, irritation and malignant growth or tumors which might be a fundamental for the treatment of a few disastrous sicknesses (Salama et al., 2015; Elmasry et al., 2018; Alotaibi et al., 2020; 2021).Vitamin B17 is called as apricot kernels or amygdalin extracted from the kernels of apricots by a biochemist named Ernst T Krebs Jr. and it is one of numerous nitrilosides which are normal cyanide containing substances (Bolarinwa et al., 2014; Elmasry et al., 2018). Vitamin B17 is a kind of sugar happening normally in plants and it is a cyanogenic diglucoside found basically in fruit kernels such as apricot, peach, cashews and macadamias (Santos Pimenta et al., 2014). Amygdalin are natural compounds that has been utilized 
as conventional Chinese medication for the treatment of numerous illnesses and it has numerous pharmacological properties include antioxidant, anti-inflammatory, antitussive, anti-asthmatic, activities (Zhou et al., 2012; Mutar et al., 2020; Tousson et al., 2020). A few examinations revealed that amygdalin can be utilized to lessen the development of prostate, renal and lung cell carcinoma (Qian et al., 2015; Juengel et al., 2016). Therefore; this study was designed the impact of vitamin B17 against growth of colitis induced variations in colon structure, AFP, CEA and PCNA- immunoreactivity.

\section{Materials and Methods}

\section{Chemical and Reagent Vitamin B17}

Vitamin B17 was purchased from the Amazon for Natural Oils Company.

\section{Acetic Acid}

Acetic acid was bought from Sigma Company and reconstituted according to the manufacture description, then diluted with saline solution to prepare $2 \%$ concentration.

\section{Animals}

Forty mice (female; $22 \pm 2 \mathrm{~g}$ ) were acquired from the animal community colony Egypt Vaccine Company, Egypt. The animals were randomized and housed under ambient room- temperature at $22-25^{\circ} \mathrm{C}$ and relative humidity conditions a 12: $12 \mathrm{~h}$ light/dark cycle, a commercial diet and water were provided ad libitum for two weeks.

\section{Induction of Ulcerative Colitis}

Mice $(n=20)$ were received $100 \mu \mathrm{L}$ of $2 \%$ acetic acid in combination with $5 \mu \mathrm{L}$ of olive oil (acetic acid/olive oil mix) using a gavage Intra-Rectally (IR) injection day by day for one week (Ali et al., 2018). Immediately after administration, the mice were hold horizontally for $2 \mathrm{~min}$ to prevent fluid leakage. Acetic acid was then retained in the colon for 30 seconds after which the fluid was withdrawn (Ali et al., 2018).

\section{Experimental Design and Animal Groups}

The mice were equally divided into four groups (10 mice in each):

G 1: Control group in which mice were received Intra-Rectal (IR) injection only $5 \mu \mathrm{L}$ of olive oil.

G 2: The mice in this group were received orally Vitamin B17 (175 mg/Kg body weight/day), for 2 weeks according to Mutar et al. (2020).

G 3: Colitis group with induced mice ulcerative colitis, mice were administrated with intra-rectal injection of $100 \mu \mathrm{L}$ of $2 \%$ acetic acid in combination with $5 \mu \mathrm{L}$ of olive oil for one week (Ali et al., 2018).
G 4: Post treated group, induced mice ulcerative colitis for one week and then treated with Vitamin B17 for another 2 weeks

\section{Sample Collection}

At the end of experiment, overnight fasted mice were euthanized, blood samples were collected from eye, centrifugation and saved in clean plug vial at $-20^{\circ} \mathrm{C}$ until measure. Sera were used for estimation of AFP and CEA. Necropsy was conducted, colon were removed, cleaned in saline solution and fixed in a 10 per cent neutral buffer formalin buffer for up to $48 \mathrm{~h}$ for histopathology and immunohistochemistry studied.

\section{Tumor Marker}

Serum Alfa Fetoproteins (AFP) and carcinoembryonic Antigen (CEA) levels were estimated with quantitative sandwich-immunoassay as indicated by Aldubayan et al. (2019).

\section{Histopathological Examination}

Colon samples were immediately taken after decapitation, washed with 0.9 saline solutions and fixed with $10 \%$ neutral buffered formalin. Following the protocol of Tousson (2016), fixed colon from each groups were stained by standard haematoxylin and eosin counterstain techniques.

\section{Immunohistochemical Investigations}

Mice colon sections were utilized to stain with PCNA following the protocol of Tousson et al. $(2011$; 2012).

\section{Statistical Analysis}

The investigation of results was finished utilizing SPSS programming adaptation 16. Information were introduced as the mean \pm SEM and the foundation for measurable hugeness was set at $\mathrm{p}<0.05$.

\section{Results}

\section{Toxicity and Clinical Symptoms}

The dose of vitamin B17 didn't inductee any reactions for the test creatures. Anal injection of mice with $2 \%$ acetic acid induced colitis with diarrhea and rectal bleeding.

\section{Tumor Markers}

\section{Changes in Serum Carcinoembryonic Antigen (CEA)}

In the current study; Fig. (1) revealed a significant elevation in CEA levels in colitis group as compared to control and vitamin B17 groups. In contrast; treatment of colitis with vitamin B17 revealed significant decrease in the CEA levels when compared with colitis group (Fig. 1). 


\section{Changes in Serum Alpha-Fetoprotein (AFP)}

In the current study; Fig. (1) revealed a significant elevation in AFP levels in colitis group as compared to control and vitamin B17 groups. In contrast; treatment of colitis with vitamin B17 revealed significant decrease in the AFP levels when compared with colitis group (Fig. 1).

\section{Histopathological investigations}

Colon sections in control mice and in mice treated with vitamin B17 groups revealed well preserved mucosal integrity with well - arranged finger like villi and their epithelial linings with a few inflammatory cells were seen to infiltrate into the villous stroma and sub mucosa (Fig. 2a and 2b).

Colon sections in colitis group as the colonic mucosa appeared atrophy, degenerated, ulcerated with shortening villus with crypt damage, depletion in goblet cell numbers and moderate marked leukocyte infiltration in the villi lamina and in sub mucosal layer (Fig. 2c). Colon sections in treated colitis with vitamin B17 revealed moderate degree of improvement as mild atrophy in villi with moderate crypt hyperplasia, mild increase in goblet cells and moderate decrease in the leukocyte infiltration (Fig. 2d).

\section{PCNA Immunoreactivity in mice colon}

Negative reactions for PCNA were observed in the mucosal layers of colon in control and in treated mice with vitamin B7 (Fig. 3a and 3b). In contrast strong positive reactions for PCNA were observed in colitis group (Fig. 3c). On the other hand; colon sections in treated colitis with vitamin B17 revealed mild positive reactions for PCNA (Fig. 3d).
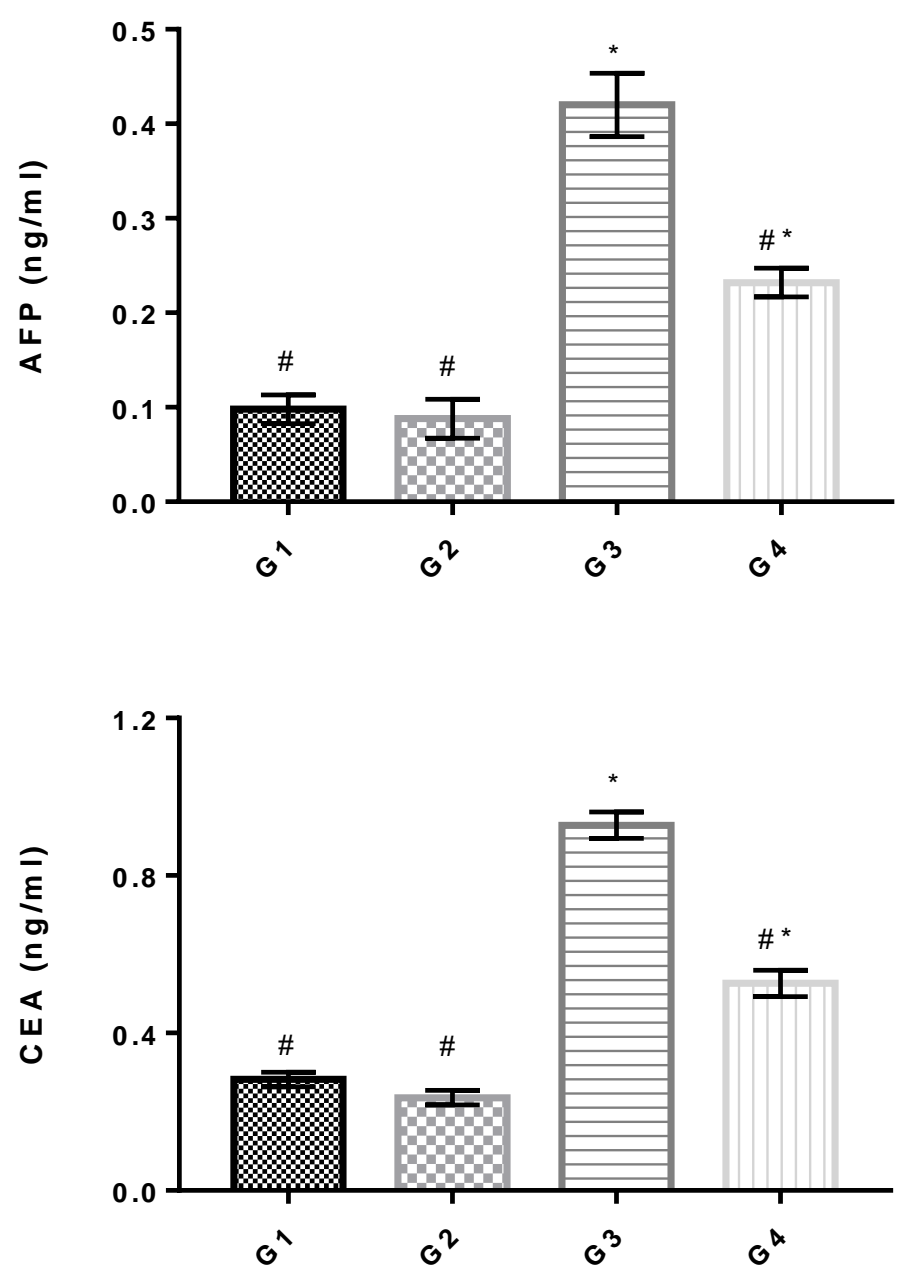

Fig. 1: Changes in the levels of Alpha Feto Proteins (AFP) and carcinoembryonic antigen (CEA) in studies groups. Data are expressed as mean \pm S.E.M of 7 observations. Where G1, control; G2, vitamin B17; G3, colitis; G4, treated colitis with vitamin B17. $\left({ }^{*}\right) \&\left({ }^{\#}\right)$ significant difference compared to control and colitis group respectively. 

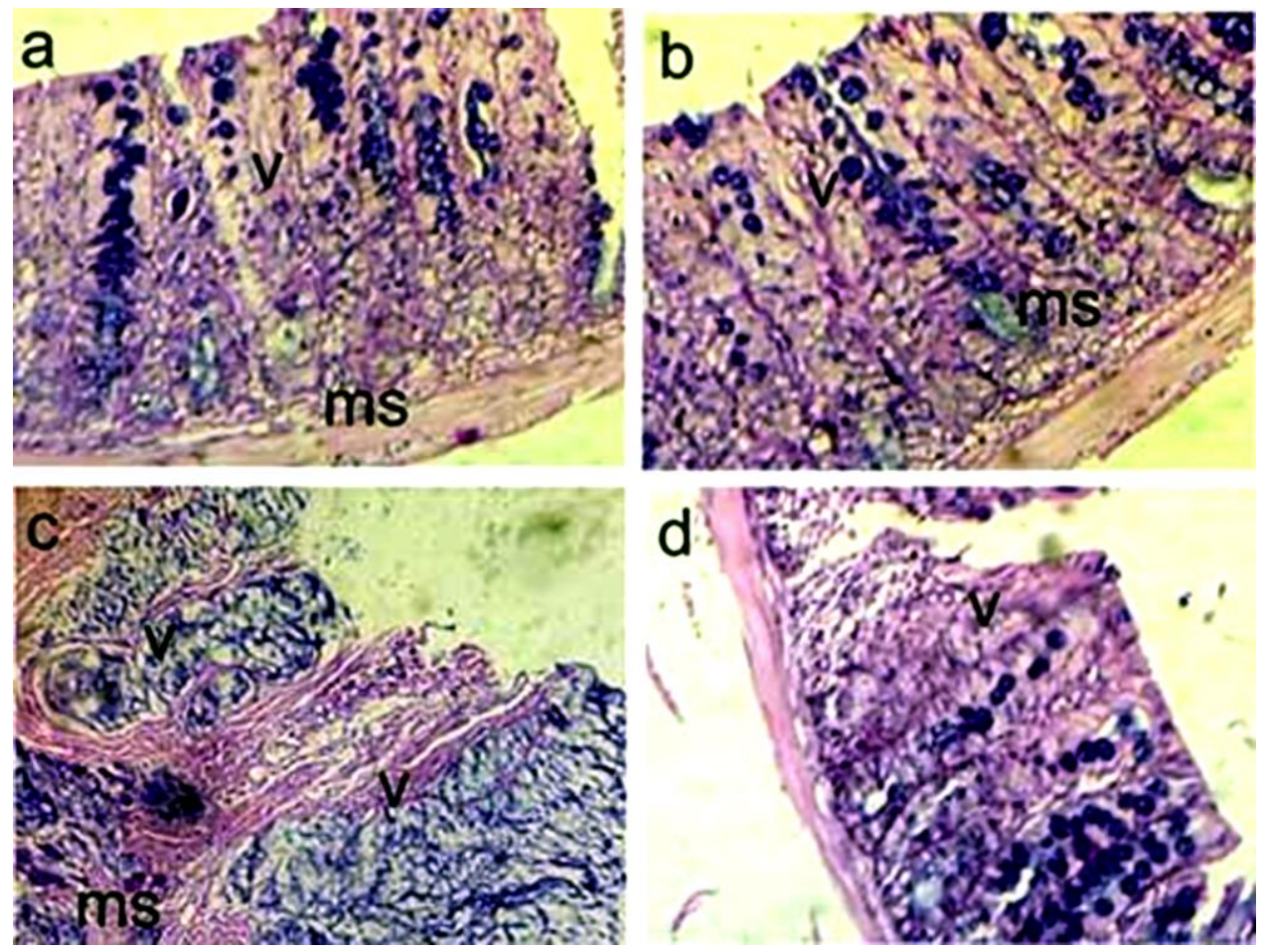

Fig. 2(a-d): Photomicrographs of mice colon sections stained by HE. (A and b): Micrographs in control and vitamin B17 groups revealed normal submucosa (ms) structure and well - preserved mucosal integrity with well - arranged finger like villi (V) and their epithelial linings. (c): Micrographs of the colon in colitis group revealed ulcerated, degenerated, shortening villus with crypt damage, depletion in goblet cell numbers and marked leukocyte infiltration. (d): Colon sections in treated colitis with vitamin B17 mild villus shortening and fusion, epithelial atrophy, moderate crypt hyperplasia and moderate to mild decrease in the leukocyte infiltration. (HE; 200X)
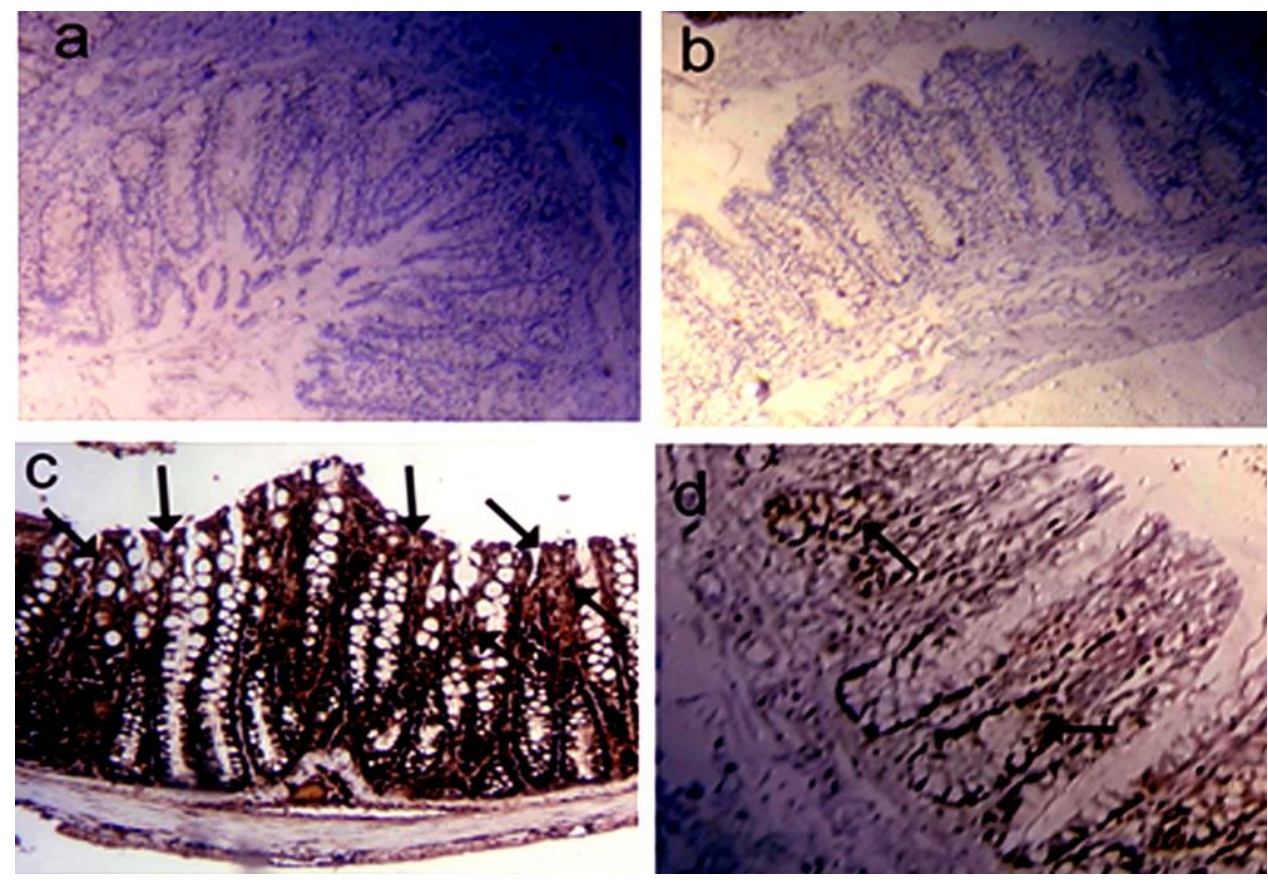

Fig. 3(a-d): Photomicrograph of PCNA in the mice colon sections. (A and b): Negative PCNA reactions in colon sections of control and vitamin B17 groups. (c): Strong positive brown immuno-reaction of PCNA (arrows) in colon section in colitis group. (d): Mild positive reactions for PCNA in colon section in treated colitis with vitamin B17. 200X 


\section{Discussion}

Currently we designed the impact of vitamin B17 against growth of colitis induced variations in colon structure, AFP, CEA and PCNA immunoreactivity. Current results showed that; anal injection of $2 \%$ acetic acid and Olive oil induced colitis with diarrhea and visible rectal bleeding. Our results agree with Ali et al. (2018) who find that; $2 \%$ acetic acid in the presence of olive oil induced colitis in albino CD1 mice.

CEA is overexpressed by an assortment of malignancies and is usually connected with colorectal disease, it can likewise be raised in different malignancies, for example, liver, pancreas, stomach and breast (Bel Hadj Hmida et al., 2001; Perkins et al., 2003). Current study revealed that a significant elevation in CEA levels in colitis group as compared to control and vitamin B17 group. In contrast; treatment of colitis with vitamin B17 revealed significant depletion in the CEA levels when compared with colitis group. Current results agree with Kamada et al. (2013) who find an increase in the levels of CEA in colitis. Current results also agree with Rocklin et al. (1991) who find that; a significant elevation in CEA and in liver function in colorectal carcinoma. Also; the current results are in agreement with Umesalma and Sudhandiran, (2010) who find that; serum CEA levels were elevated with $\mathrm{DMH}$-induced colon cancer in rats.

AFP is a tumor-related fetal glycoprotein containing $3-4 \%$ sugar moieties and is a plasma protein delivered by the early stage yolk sac and the fetal liver. AFP levels in serum, amniotic liquid and pee works as a screening test for innate inabilities, chromosomal variations from the norm, just as some other grown-up happening tumors and pathologies (Shumway et al., 1996). Current investigation; uncovered a critical increment in the degrees of AFP in colitis bunch when contrasted with control and nutrient B17 gatherings while treatment of colitis with nutrient B17 uncovered huge diminishing in the AFP when contrasted with colitis gathering. Our outcomes concur with Thompson et al. (1974) who revealed that; an expansion in the degrees of AFP in ulcerative colitis and territorial enteritis. Additionally Linson and Hanauer (2019) considers the potential and significant job of AFP in incendiary gut infection.

Many abnormalities were reported in mouse colon after $2 \%$ acetic acid induced colitis as a marked atrophy, degenerated, ulcerated with shortening villus with crypt damage, depletion in goblet cell numbers and moderate marked leukocyte infiltration in the villi lamina and in sub mucosal layer. Colitis was experimentally induced by acetic acid anal injection and it is similar to human ulcerative colitis in inflammation and ulcers of the colon and rectum. These results agree with Ali et al. (2018) who find that; 1, 2 and 4\% acetic acid induced colitis with many changes in mucosa and in sub mucosa layers in CD1 albino mice. PCNA is one antigen used to calculate a proliferation index and is a non- histone protein detected 1 st in the mid-G1 phase of the cell cycle, reaching a maximum in $\mathrm{S}$ and declining in G2 (Tousson et al., 2014). Current results revealed that; colitis induced an increase in PCNA immunoreactivity as compared to control group and treatments of colitis with vitamin B17 inhibit this PCNA elevation. Our results agree with Sipos et al. (2005) who reported that; an increased in proliferation and apoptosis expression in inflammatory bowel diseases. Also; current results agree with Sjöqvist et al. (1999) who reported increased expression of proliferative Ki-67 nuclear antigen is correlated with dysplastic colorectal epithelium in ulcerative colitis. Vitamin B17 extract have the ability to improve the colon functions and structure, inhibit the proliferations, AFP and CEA. If established in human beings, these outcomes could recommend th at; vitamin B17 can be utilized as an adjuvant treatment with chemotherapy drugs in the treatments of different types of cancer and tumors.

\section{Author's Contributions}

This work was carried out in collaboration among all authors. 'Gihan Abd Elsamie, Sabah El-Banna, Ehab Tousson and Shatha Felemban designed the study, performed the statistical analysis and wrote the protocol, Mohanad Hussein wrote the first draft of the manuscript, managed the analyses of the study and managed the literature searches. 'All authors read and approved the final manuscript

\section{Ethics}

This article is original and contains unpublished material. The corresponding author confirms that have read and approved the manuscript and no ethical issues involved.

\section{References}

Abd Eldaim, M. A., Tousson, E., El Sayed, I. E. T., \& Awd, W. M. (2019a). Ameliorative effects of Saussurea lappa root aqueous extract against Ethephon-induced reproductive toxicity in male rats. Environmental toxicology, 34(2), 150-159. https://doi.org/10.1002/tox.22669

Abd Eldaim, M.A., Tousson, E., El Sayed, I. E., El, A. E., \& Elsharkawy, H. N. (2019b). Grape seeds proanthocyanidin extract ameliorates Ehrlich solid tumor induced renal tissue and DNA damage in mice. Biomedicine \& Pharmacotherapy, 115:108908

Aldubayan, M. A., Elgharabawy, R. M., Ahmed, A. S. \& Tousson, E. (2019). Antineoplastic Activity and Curative Role of Avenanthramides against the Growth of Ehrlich Solid Tumors in Mice. Oxidative Medicine and Cellular Longevity, 12. https://doi.org/10.1155/2019/5162687 
Ali, D. A., Salem, M. \& Tousson, E. M. (2018). Administration of olive oil optimizes acetic acid induced colitis in CD1 mice. International Journal of Cancer and Biomedical Research, 2(2), 1-8.

Alotaibi, B., El-Masry, T. A., Tousson, E., Alarfaj, S. J., \& Saleh, A. (2020). Therapeutic effect of rocket seeds (Eruca sativa L.) against hydroxyapatite nanoparticles injection induced cardiac toxicity in rats. Pak. J. Pharm. Sci., 33(4), 1839-1845.

Alotaibi, B., Tousson, E., El-Masry, T. A., Altwaijry, N., \& Saleh, A. (2021). Ehrlich ascites carcinoma as model for studying the cardiac protective effects of curcumin nanoparticles against cardiac damage in female mice. Environmental Toxicology, 36(1),10513. https://doi.org/10.1002/tox.23016

Altwaijry, N., El-Masry, T. A., Alotaibi, B., Tousson, E., \& Saleh, A. (2020). Therapeutic effects of rocket seeds (Eruca sativa L.) against testicular toxicity and oxidative stress caused by silver nanoparticles injection in rats. Environmental Toxicology, 35(9), 952-960.

Altwaijry, N., El-Masry, T. A., Alotaibi, B. S., Tousson, E., Alodhayani, A.A., El-Morshedy, K., Elmaghed, N.A., Sayed, A.E., \& Saleh, A. (2021). Potential therapeutic effects of avenanthramide-C against lung toxicity caused by silver nanoparticles injection in rats. Pak. J. Pharm. Sci., 34(1),337-43.

Antoniou, E., Margonis, G. A., Angelou, A., Pikouli, A., Argiri, P., Karavokyros, I., Papalois, A., \& Pikoulis, E. (2016). The TNBS-induced colitis animal model: an overview. Annals of medicine and surgery, 11,915. https://doi.org/10.1016/j.amsu.2016.07.019

Bel Hadj Hmida, Y., Tahri, N., \& Sellami, A. (2001). Sensitivity, specificity and prognostic value of CEA in colorectal cancer: results of a Tunisian series and literature review. Tunis Med, 79,434-440.

Bolarinwa, I. F., Orfila, C. \& Morgan, M. R. (2014). Amygdalin content of seeds, kernels and food products commercially-available in the UK. Food chemistry, 152, 133-139. https://doi.org/10.1016/j.foodchem.2013.11.002

Cengiz, D., Gürçay, E., Karaahmet, Ö. Z., Karaahmet, F., Umay, E. \& Çakcı, A. (2017). Inflammatory arthritis complicated by inflammatory bowel disease: two case reports. Turkish Journal of Physical Medicine and Rehabilitation, 63(3), 266. https://doi.org/10.5606/tftrd.2017.23169

Elmasry, T. A., Al-Shaalan, N. H., Tousson, E., ElMorshedy, K. \& Al-Ghadeer, A. (2018). Star anise extracts modulation of reproductive parameters, fertility potential and DNA fragmentation induced by growth promoter Equigan in rat testes. Brazilian Journal of Pharmaceutical Sciences, 54(1). https://doi.org/10.1590/s2175-97902018000117261
Hanauer, S. B. (2006). Inflammatory bowel disease: epidemiology, pathogenesis and therapeutic opportunities. Inflammatory bowel diseases, 12(1), 3-9. https://doi.org/10.1097/01.MIB.0000195385.19268.68

Juengel, E., Maxeiner, S., Rutz, J., Justin, S., Roos, F., Khoder, W., Tsaur, I., Nelson, K., Bechstein, W. O., Haferkamp, A. \& Blaheta, R. A. (2016). Sulforaphane inhibits proliferation and invasive activity of everolimus-resistant kidney cancer cells in vitro. Oncotarget, $\quad 7(51), \quad 85208$. https://doi.org/10.18632/oncotarget.13421

Kamada, N., Seo, S. U., Chen, G. Y. \& Núñez, G. (2013). Role of the gut microbiota in immunity and inflammatory disease. Nat Rev Immunol, 13, 321335. https://doi.org/10.1038/nri3430

Linson, E. A. \& Hanauer, S. B. (2019). More Than a Tumor Marker... A Potential Role for Alpha-Feto Protein in Inflammatory Bowel Disease. Inflammatory bowel diseases, 25(7),1271-6. https://doi.org/10.1093/ibd/izy394

Mutar, T. F., Tousson, E., Hafez, E., Gazia, M. A. \& Salem, S.B. (2020). Ameliorative effects of vitamin B17 on the kidney against Ehrlich ascites carcinoma induced renal toxicity in mice. Environmental Toxicology, 35(4), 528-537. https://doi.org/10.1002/tox.22888

Ohlsson, B. (2015). New insights and challenges in microscopic colitis. Therapeutic advances in gastroenterology, $\quad 8(1), \quad 37-47$. https://doi.org/10.1177/1756283X14550134

Perkins, G. L., Slater, E. D., Sanders, G. K. \& Prichard, J. G. (2003). Serum tumor markers. Am Fam Physician, 15,1075-1082.

Qian, J., Henderson, W. A., Xu, W., Bhattacharya, P., Engelhard, M., Borodin, O. \& Zhang, J. G. (2015). High rate and stable cycling of lithium metal anode. Nature communications, 6, 6362. https://doi.org/10.1038/ncomms7362

Radko, L. \& Cybulski, W. (2007). Application of silymarin in human and animal medicine. Journal of Pre-Clinical and Clinical Research, 1(1).

Randhawa, P. K., Singh, K., Singh, N. \& Jaggi, A. S. (2014). A review on chemical-induced inflammatory bowel disease models in rodents. The Korean journal of physiology \& pharmacology, 18(4), 279-88. https://doi.org/10.4196/kjpp.2014.18.4.279

Rocklin, M. S., Senagore, A. J. \& Talbott, T. M. (1991). Role of carcinoembryonic antigen and liver function tests in the detection of recurrent colorectal carcinoma. Diseases of the colon \& rectum, 34(9), 794-7. https://doi.org/10.1007/BF02051073

Saad, R. E., Shobar, R. M., Jakate, S. \& Mutlu, E. A. (2019). Development of collagenous colitis in inflammatory bowel disease: two case reports and a review of the literature. Gastroenterology Report, 7(3), 218-22. https://doi.org/10.1093/gastro/gox026 
Salama, A. F., Kasem, S. M., Tousson, E. \& Elsisy, M. K. (2015). Protective role of L-carnitine and vitamin E on the testis of atherosclerotic rats. Toxicology and industrial health, 31(5),467-74. https://doi.org/10.1177/0748233712472523

Salama, A. F., Tousson, E., Shalaby, K. A. \& Hussien, H. T. (2014). Protective effect of curcumin on chloroform as by-product of water chlorination induced cardiotoxicity. Biomedicine \& Preventive Nutrition, $\quad 4(2), \quad 225-30$. https://doi.org/10.1016/j.bionut.2014.02.004

Santos Pimenta, L. P., Schilthuizen, M., Verpoorte, R. \& Choi, Y. H. (2014). Quantitative Analysis of Amygdalin and Prunasin in Prunus serotina Ehrh. using 1H-NMR Spectroscopy. Phytochemical analysis, 25(2), 122-6. https://doi.org/10.1002/pca.2476

Shumway, J. B., Greenspoon, J. S., Khouzami, A. N., Piatt, L. D. \& Blakemore, K.J. (1996) Amniotic fluid alpha fetoprotein (AFAFP) and maternal serum alpha fetoprotein (MSAFP) in abdominal pregnancies: correlation with extent and site of placental implantation and clinical implications. Journal of Maternal-Fetal Medicine, 5(3), 120-3.

Sipos, F., Molnár, B., Zágoni, T., Berczi, L. \& Tulassay, Z. (2005). Growth in epithelial cell proliferation and apoptosis correlates specifically to the inflammation activity of inflammatory bowel diseases: ulcerative colitis shows specific p53-and EGFR expression alterations. Diseases of the colon \& rectum, 48(4), 775-86. https://doi.org/10.1007/s10350-004-0831-5

Sjöqvist, U., Öst, Å. \& Löfberg, R. (1999). Increased expression of proliferative $\mathrm{Ki}-67$ nuclear antigen is correlated with dysplastic colorectal epithelium in ulcerative colitis. International journal of colorectal disease, 14(2), 107-13. https://doi.org/10.1007/s003840050194

Tahan, G., Aytac, E., Aytekin, H., Gunduz, F., Dogusoy, G., Aydin, S., Tahan, V. \& Uzun, H. (2011). Vitamin $E$ has a dual effect of anti-inflammatory and antioxidant activities in acetic acid-induced ulcerative colitis in rats. Canadian Journal of Surgery, 54(5), 333. https://doi.org/10.1503/cjs.013610

Thompson, W. G., Gillies, R. R., Silver, H. K., Shuster, J., Freedman, S. O. \& Gold, P. (1974). Carcinoembryonic antigen and alpha1-fetoprotein in ulcerative colitis and regional enteritis. Canadian Medical Association Journal, 110(7), 775.
Tousson, E. (2016). Histopathological alterations after a growth promoter boldenone injection in rabbits. Toxicology and Industrial Health, 32(2), 299-305. https://doi.org/10.1177/0748233713500821

Tousson, E., Alghabban, A. J., \& Harga, H. A. (2014). Thyroidectomy induced hepatic toxicity and possible amelioration by Ginkgo biloba leaf extract. Biomedicine \& Preventive Nutrition, 4(3), 39-7. https://doi.org/10.1016/j.bionut.2014.06.001

Tousson, E., Ali, E. M., Ibrahim, W. \& Ashraf, R. M. (2012). Histopathological and immunohistochemical alterations in rat heart after thyroidectomy and the role of hemin and ketoconazole in treatment. Biomedicine \& Pharmacotherapy, 66(8), 627-32. https://doi.org/10.1016/j.biopha.2012.08.009

Tousson, E., Ali, E. M., Ibrahim, W. \& Mansour, M. A. (2011). Proliferating cell nuclear antigen as a molecular biomarker for spermatogenesis in PTUinduced hypothyroidism of rats. Reproductive sciences, $18(7), \quad 679-86$. https://doi.org/10.1177/1933719110395401

Tousson, E., Bayomy, M. F., \& Ahmed, A. A. (2018). Rosemary extract modulates fertility potential, DNA fragmentation, injury, KI67 and P53 alterations induced by etoposide in rat testes. Biomedicine \& Pharmacotherapy, https://doi.org/10.1016/j.biopha.2018.01.025

Tousson, E., El-Atrsh, A., Mansour, M., \& Abdallah, A. (2019). Modulatory effects of Saussurea lappa root aqueous extract against ethephon-induced kidney toxicity in male rats. Environmental Toxicology, 34(12),1277-1284. https://doi.org/10.1002/tox.22828

Tousson, E., Hafez, E., Gazia, M. M., Salem, S. B. \& Mutar, T.F. (2020). Hepatic ameliorative role of vitamin B17 against Ehrlich ascites carcinomainduced liver toxicity. Environmental Science and Pollution Research, 27, 9236-9246. https://doi.org/10.1007/s11356-019-06528-6

Umesalma, S. \& Sudhandiran, G. (2010). Differential inhibitory effects of the polyphenol ellagic acid on inflammatory mediators NF- $\kappa \mathrm{B}$, iNOS, COX-2, TNF- $\alpha$, and IL-6 in 1, 2-dimethylhydrazine-induced rat colon carcinogenesis. Basic \& clinical pharmacology \& toxicology, 107(2), 650-5. https://doi.org/10.1111/j.1742-7843.2010.00565.x

Zhou, K. \& Raffoul, J. J. (2012). Potential anticancer properties of grape antioxidants. J Oncology, 803294 (8). https://doi.org/10.1155/2012/803294 